INTERNATIONAL JOURNAL OF RESEARCHES IN BIOSCIENCES, AGRICULTURE AND TECHNOLOGY

(C) VISHWASHANTI MULTIPURPOSE SOCIETY (Global Peace Multipurpose Society) R. No. MH-659/13(N) www.vmsindia.org

\title{
STRUCTURAL CHRACTERIZATION OF AQUEOUS AMINO ACIDS THROUGH ADIABATIC COMPRESSIBILITY MEASUREMENT AT 308.15K
}

\author{
A. T. Shende \\ Dept. of Engineering Physics, Jagadambha College of Engineering and Technology, \\ Yavatmal (MS), India \\ amardeepshende@gmail.com
}

\begin{abstract}
:
Adiabatic compressibility of amino acids has been measured by ultrasonic technique at frequency $4 \mathrm{MHz}$ and ionization of side chain and solvation effects are discussed. The same data is used to characterize the structure of amino acids. The negative slope of adiabatic compressibility with molar concentration indicating the existence of dynamic domains within the system. For this study ultrasonic velocity and density were measured in six aqueous amino acids namely; L-Alanine, L-Aspartic Acid, L-Glutamic Acid, L-Glutamine, L-Phenylalanine and L-Valine of different concentration at $308.15 \mathrm{~K}$. Adiabatic compressibility was evaluated using experimentally determined ultrasonic velocity and density and the same used for structural characterization of aqueous amino acids.
\end{abstract} Keywords: ultrasonic velocity, density, amino acid structure, volume fluctuations

\section{Introduction}

The ultrasonic wave in fluid causes alternating compression and rarefactions. Within the system of pressure wave and fluid, time required for thermal equilibrium of the solution is more than time period of compression and rarefaction. Hence the process is reversible and adiabatic. By using these ultrasonic pressure waves, one can extract information about mechanical and thermal properties of the system.

The theory of ultrasonic wave propagation in solution can be found in standard texts.[1] The property of a substance capable of being reduced in volume by application of pressure is known as compressibility. The adiabatic compressibility is defined by $\beta_{\mathrm{ad}}=-1 / \mathrm{V}(\partial \mathrm{V} / \partial \mathrm{P})_{\mathrm{s}}$ where $\mathrm{V}$ is the volume of the sample and $\mathrm{P}$ is the pressure. $\beta_{\mathrm{ad}}$ can be obtained by a measurement of the density $\rho$ and ultrasonic velocity $u$ : $\beta_{\mathrm{ad}}=1 / \rho \mathrm{u}^{2}$. For a solution containing amino acids, the adiabatic compressibility of amino acids may be determined by measuring the density and

\section{Observations and Graphs}

Table: 1. ultrasonic velocity, density and adiabatic compressibility for aqueous L-Alanine (Mol.Wt. $89.09)$ at $308.15 \mathrm{~K}$

\begin{tabular}{|l|l|l|l|l|}
\hline S.No. & Molarities & $(\mathbf{u}) \mathbf{( m / s )}$ & $(\mathbf{p})\left(\mathbf{K g} / \mathbf{m}^{\mathbf{3}}\right)$ & $\left(\boldsymbol{\beta}_{\mathbf{a d}}\right)\left(\mathbf{m}^{\mathbf{2}} / \mathbf{N}\right.$ or $\left.\mathbf{P a} \mathbf{a}^{-1}\right)$ \\
\hline 1 & 0.0000 & 1522.73 & 0.99393 & $4.33909 \mathrm{E}-07$ \\
\hline 2 & 0.0075 & 1518.51 & 1.00372 & $4.32068 \mathrm{E}-07$ \\
\hline 3 & 0.0080 & 1519.77 & 1.00173 & $4.32209 \mathrm{E}-07$ \\
\hline 4 & 0.0085 & 1522.44 & 1.00834 & $4.27871 \mathrm{E}-07$ \\
\hline 5 & 0.0090 & 1537.45 & 1.02697 & $4.11946 \mathrm{E}-07$ \\
\hline 6 & 0.0095 & 1530.39 & 1.01320 & $4.21406 \mathrm{E}-07$ \\
\hline 7 & 0.0100 & 1532.88 & 1.01590 & $4.18922 \mathrm{E}-07$ \\
\hline
\end{tabular}

Table: 2. ultrasonic velocity, density, and adiabatic compressibility for aqueous L- Aspartic Acid (Mol.Wt. 133.10) at 308.15K

\begin{tabular}{|c|c|c|c|c|c|}
\hline & S.No. & Molarities & (u) $(\mathrm{m} / \mathrm{s})$ & $(\rho)\left(\mathrm{Kg} / \mathrm{m}^{3}\right)$ & $\left(\beta_{\mathrm{ad}}\right)\left(\mathrm{m}^{2} / \mathbf{N}\right.$ or $\left.\mathbf{P a}^{-1}\right)$ \\
\hline & 1 & 0.0000 & 1522.73 & 0.99393 & 4.33909E-07 \\
\hline & 2 & 0.0075 & 1506.77 & 1.00283 & $4.39217 \mathrm{E}-07$ \\
\hline & 3 & 0.0080 & 1521.13 & 1.00140 & $4.31578 \mathrm{E}-07$ \\
\hline & 4 & 0.0085 & 1543.16 & 1.01474 & $4.13831 \mathrm{E}-07$ \\
\hline & 5 & 0.0090 & 1540.45 & 1.01231 & $4.16285 \mathrm{E}-07$ \\
\hline & 6 & 0.0095 & 1544.35 & 1.01978 & $4.11152 \mathrm{E}-07$ \\
\hline & 7 & 0.0100 & 1555.55 & 1.02086 & $4.04824 \mathrm{E}-07$ \\
\hline
\end{tabular}

ultrasonic velocity in the solution as a function of amino acid concentration. In recent years adiabatic compressibility is important parameter and has been valuable to find molecular interaction and structural determination at molecular basis [7-9]. In this paper the characteristic importance of adiabatic compressibility towards determination of structure of aqueous amino acid is discussed.

\section{Methods and Materials}

All the given sample L-Alanine, LAspartic Acid, L-Glutamic Acid, L-Glutamine, LPhenylalanine and L-Valine were in pure form (E- Merck grade).Different concentration $(0.0075 \mathrm{M}, 0.008 \mathrm{M}, 0.0085 \mathrm{M}, 0.009 \mathrm{M}, 0.0095 \mathrm{M}$, $0.01 \mathrm{M})$ of each sample of were made with doubled distilled water. Densities and ultrasonic velocities were measured at 308.15 K. Densities were determine with Density Bottle with plunger method and ultrasonic velocities with Pluse Echo Overlap Method using Innovative Instrument-102 (AUAR) along with Ultrasonometer $(4 \mathrm{MHz})$ and Universal Time \& Frequency Counter. 
Table: 3. ultrasonic velocity, density and adiabatic compressibility for aqueous L- Glutamic Acid (Mol.Wt. 147.13) at 308.15K

\begin{tabular}{|l|l|l|l|l|}
\hline S.No. & Molarities & $(\mathbf{u}) \mathbf{( m / \mathbf { s } )}$ & $\mathbf{( p )}\left(\mathbf{K g} / \mathbf{m}^{\mathbf{3}}\right)$ & $\mathbf{( \beta a d}_{\mathbf{a d}}\left(\mathbf{m}^{\mathbf{2}} / \mathbf{N}\right.$ or $\mathbf{P a}^{-1} \mathbf{)}$ \\
\hline 1 & 0.0000 & 1522.73 & 0.99393 & $4.33909 \mathrm{E}-07$ \\
\hline 2 & 0.0075 & 1509.83 & 1.00498 & $4.36502 \mathrm{E}-07$ \\
\hline 3 & 0.0080 & 1519.57 & 1.00622 & $4.30393 \mathrm{E}-07$ \\
\hline 4 & 0.0085 & 1547.00 & 1.02667 & $4.06994 \mathrm{E}-07$ \\
\hline 5 & 0.0090 & 1532.50 & 1.01211 & $4.20699 \mathrm{E}-07$ \\
\hline 6 & 0.0095 & 1534.23 & 1.01511 & $4.1851 \mathrm{E}-07$ \\
\hline 7 & 0.0100 & 1541.75 & 1.01621 & $4.13989 \mathrm{E}-07$ \\
\hline
\end{tabular}

Table: 4. ultrasonic velocity, density and adiabatic compressibility for aqueous L-Glutamine (Mol.Wt. $146.15)$ at $308.15 \mathrm{~K}$

\begin{tabular}{|l|l|l|l|l|}
\hline S.No. & Molarities & $(\mathbf{u})(\mathbf{m} / \mathbf{s})$ & $(\mathbf{p})\left(\mathbf{K g} / \mathbf{m}^{\mathbf{3}}\right)$ & ${\left(\mathbf{\beta a d}_{\mathbf{a d}}\right)\left(\mathbf{m}^{\mathbf{2}} / \mathbf{N} \text { or } \mathbf{P a}^{-1}\right)}^{\mathbf{1})}$ \\
\hline 1 & 0.0000 & 1522.73 & 0.99393 & $4.33909 \mathrm{E}-07$ \\
\hline 2 & 0.0075 & 1521.15 & 0.99888 & $4.32656 \mathrm{E}-07$ \\
\hline 3 & 0.0080 & 1532.70 & 1.01299 & $4.20224 \mathrm{E}-07$ \\
\hline 4 & 0.0085 & 1525.11 & 1.00950 & $4.25884 \mathrm{E}-07$ \\
\hline 5 & 0.0090 & 1527.32 & 1.01870 & $4.20817 \mathrm{E}-07$ \\
\hline 6 & 0.0095 & 1530.25 & 1.02537 & $4.1648 \mathrm{E}-07$ \\
\hline 7 & 0.0100 & 1529.97 & 1.02659 & $4.16138 \mathrm{E}-07$ \\
\hline
\end{tabular}

Table: 5. ultrasonic velocity, density and adiabatic compressibility for aqueous L-Phenylalanine (Mol.Wt. 165.19) at 308.15K

\begin{tabular}{|c|c|c|c|c|}
\hline S.No. & Molarities & (u) $(\mathrm{m} / \mathrm{s})$ & (p) $\left(\mathrm{Kg} / \mathrm{m}^{3}\right)$ & $\left(\beta_{a d}\right)\left(m^{2} / \mathbf{N}\right.$ or $\left.\mathbf{P a}^{-1}\right)$ \\
\hline 1 & 0.0000 & 1522.73 & 0.99393 & $4.33909 \mathrm{E}-07$ \\
\hline 2 & 0.0075 & 1511.29 & 1.03954 & $4.21176 \mathrm{E}-07$ \\
\hline 3 & 0.0080 & 1517.21 & 1.04834 & $4.14387 \mathrm{E}-07$ \\
\hline 4 & 0.0085 & 1520.01 & 1.04047 & $4.15985 \mathrm{E}-07$ \\
\hline 5 & 0.0090 & 1522.83 & 1.04751 & $4.1166 \mathrm{E}-07$ \\
\hline 6 & 0.0095 & 1528.75 & 1.05506 & $4.05555 \mathrm{E}-07$ \\
\hline 7 & 0.0100 & 1533.51 & 1.05796 & $401937 \mathrm{~F}-07$ \\
\hline
\end{tabular}

Table: 6. ultrasonic velocity, density and adiabatic compressibility for aqueous L-Valine (Mol.Wt. $117.15)$ at $308.15 \mathrm{~K}$

\begin{tabular}{|c|c|c|c|c|}
\hline S.No. & Molarities & (u) $(\mathrm{m} / \mathrm{s})$ & (p) $\left(\mathrm{Kg} / \mathrm{m}^{3}\right)$ & $\left(\beta_{a d}\right)\left(m^{2} / N\right.$ or $\left.\mathrm{Pa}^{-1}\right)$ \\
\hline 1 & 0.0000 & 1522.73 & 0.99393 & $4.33909 \mathrm{E}-07$ \\
\hline 2 & 0.0075 & 1507.52 & 1.00588 & $4.37449 \mathrm{E}-07$ \\
\hline 3 & 0.0080 & 1518.42 & 1.00409 & $4.3196 \mathrm{E}-07$ \\
\hline 4 & 0.0085 & 1526.33 & 1.00920 & $4.2533 \mathrm{E}-07$ \\
\hline 5 & 0.0090 & 1531.85 & 1.01212 & $4.21052 \mathrm{E}-07$ \\
\hline 6 & 0.0095 & 1533.67 & 1.01642 & $4.18276 \mathrm{E}-07$ \\
\hline 7 & 0.0100 & 1537.71 & 1.01758 & $4.15607 \mathrm{E}-07$ \\
\hline
\end{tabular}

\section{Graphs}

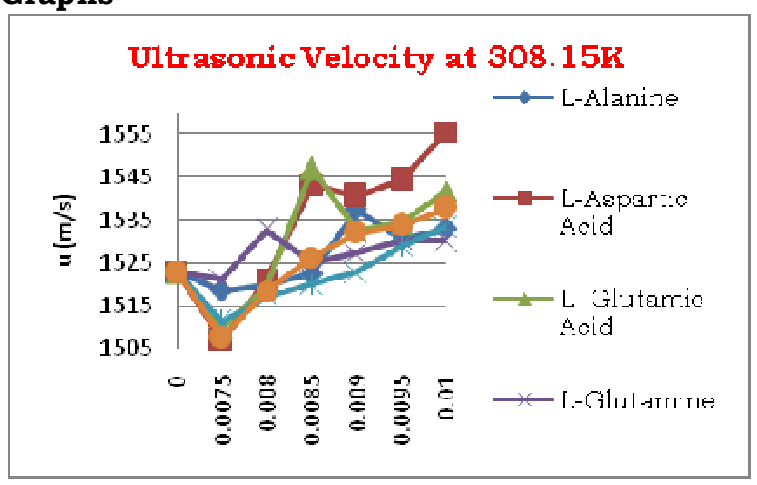

Figure. 1

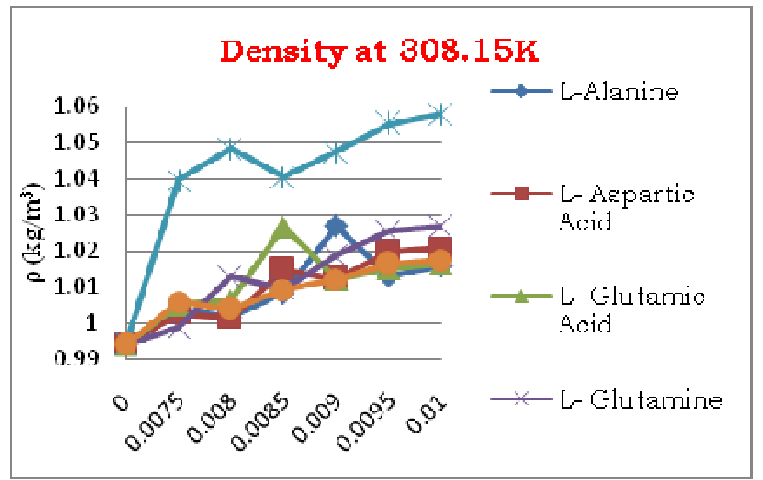

Figure. 2 


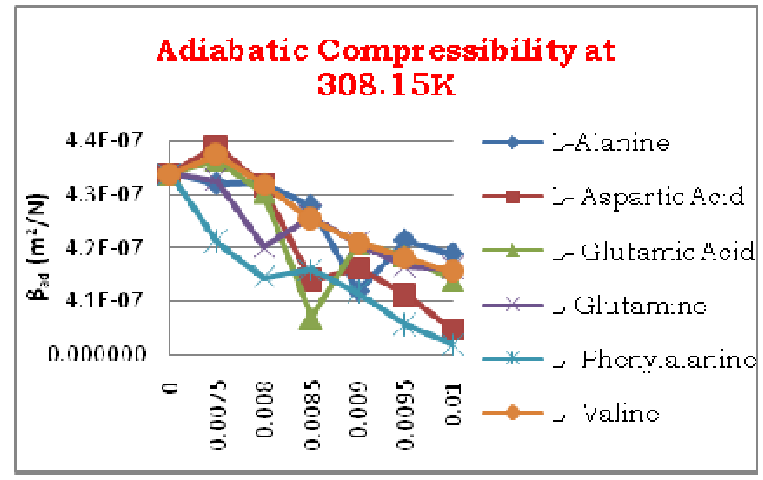

Figure.3

Figure. 1,2,3: ultrasonic velocity, density and adiabatic compressibility for six different amino acids namely L- Alanine,L-Aspartic Acid, LGlutamic Acid, L- Glutamine, L- Phenylalanine and L- Valine

\section{Discussion}

Compressibility is a volume property of the system. The total volume of the solution is given by

$V_{T}=\sum_{i} N_{i} V_{i}$

Where ' $i$ ' is for ith species. The adiabatic compressibility is

$$
\beta_{a d}=-\frac{-1}{V_{T}}\left(\frac{\partial V_{T}}{\partial P}\right)_{s}=-\frac{1}{V_{T}} \sum_{i}\left[N_{i}\left(\frac{\partial V_{i}}{\partial P}\right)_{s}+V_{i}\left(\frac{\partial N_{i}}{\partial P}\right)_{s}\right]=\Sigma_{i}\left[\left(v_{i} \beta_{i}\right)-\frac{V_{i}}{V_{T}}\left(\frac{\partial N_{i}}{\partial P}\right)_{s}\right]
$$

Where $\beta_{\mathrm{i}}$ is the intrinsic adiabatic compressibility of the ith species. $\mathrm{v}_{\mathrm{i}}$ is the fractional volume of the ith species. The first term of above equation states that the total compressibility of solution is the volume average of the compressibility of the system under consideration and depends on the chemical relaxation process. In particular, if one existing equilibrium is pressure dependent i.e. $\Delta V_{i} \neq 0$ in the corresponding free energy term, it contributes to the solution adiabatic compressibility. Using this one can obtained expressions for isomerization, proton transfer, solvation, coupled equilibrium reaction etc.

Density and velocity in the solution are directly measurable quantities. The volume fraction (v) is the fractional weight of the amino acid times the ratio of the density of the amino acid to the density of the solution. From these data we can extract an upper limit for the intrinsic amino acid compressibility by estimating an upper limit for the contribution of the bound water to the total solution compressibility. The bound water is clearly nonhomogenous. In a rough approximation we can distinguish three different kinds: (a) water bound to charge groups, (b) water bound to the amide group and (c) water organized around

\section{Result}

The liquid system taken for the present investigation were L-Alanine, L-Aspartic Acid, LGlutamic Acid, L-Glutamine, L-Phenylalanine and L-Valine having conc. $0.0075 \mathrm{M}, 0.008 \mathrm{M}$, $0.0085 \mathrm{M}, \quad 0.009 \mathrm{M}, 0.0095 \mathrm{M}$, and $0.01 \mathrm{M}$. Experimentally values of Densities, and Ultrasonic velocities with different concentration at $308.15 \mathrm{~K}$ were determined as shown in Table 1, Table 2 , Table 3, Table 4 , Table 5 and Table 6. Adiabatic compressibility of above systems calculated from experimentally determined ultrasonic velocities and densities and reported at last column of each table. water already bound and around other group [79]. Only bound water with different compressibility than bulk water needs to be distinguished from bulk water. We assume that the electrostricted water bound to charged groups make the dominant contribution. The compressibility of the electrostricted water is probably very low. The adiabatic compressibility values obtained for different amino acids are listed in table 1 to 6 . The intrinsic compressibility is small but not negligible. An additional correction to the compressibility derives from the relaxation contribution due to proton transfer equilibrium at the ionizable side chains [2, 13-20]. The decrease in adiabatic compressibility fig3 for all amino acids can be explained solely by changes in solvation. It also believes that the decrease reflects a contribution from the internal amino acid structure: covalently bonded structure and weakly bonded stricture. A compressibility experiment measures essentially the fluctuation in volume associated with dynamic processes taking place in the amino acid system. These dynamic processes can be conformational fluctuations or chemical processes at the amino acid surface. The latter are typically ionization and solvation of side chain which have been extensively characterized. 


\section{Conclusion}

The negative slope of adiabatic compressibility with molar concentration indicating the existence of dynamic domains within the system. This can be used to study the structural characterization of aqueous amino acid.

\section{Acknowledgments}

The author wishes to express thanks to Secretory Dr. Shittal Watile, and Director Shri Pawan Watile, Jagadambha Bahuddessiya Gramin Vikas Sanstha, Yavatmal for consistently encouraging and boosting for presenting this paper. The author also acknowledges Dr. S.K. Kalaspurkar, Principal, Jagadambha College of Engineering \& Technology, Yavatmal for their valuable suggestion and ideas.

\section{References}

[1] Stuehr J. \& Yeager E. (1965): Physical Acoustics, ed. W.P. Mason (Academic, New York), Vol.11A, pp.351-452.

[2] Sarvazyan A.P. \& Hemmes P. (1979): Biopolymers 18, 3015-3024

[3] Sarvazyan A.P. Kharakoz D.P. \& Hemmes P. (1979): J. Phys. Chem

[4] Gekko K. \& Noguchi H. (1979): J.Phys.Chem. 83, 2706-2714

[5] Millero F.J., , Ward G.K \& Chetirkin P. (1976):J.Biol.Chem. 2517, 4001-4004

[6] Slutsky L.J. \& Madsen L.(1977):IEEE Ultrason.Symp. eds. J.Deklerk \& B.P. McAvoy ,pp 148-152,
[7] Careri G., Giansanti A.\& Gratton E. (1979): Bioploymers 18, 1187-1203

[8] Kuntz I.D. Jr \& Kauzmann W. (1974): Adv. Protien Chem. 28,239-347

[9] Bull H.B. \& Breese K. (1968): Arch. Biochem, Biophys, 128, 488-502

[10] Millero F.K. , Lo Surdo A.\& Shin C. (1978): J. Phys. Chem ,82, 784-792

[11] Miyahara Y. (1953:)Bull Chem. Soc Jpn., 26,390-393

[12] Laliberte L.H. \& Conway B.E. (1970): J.Phys. Chem, 74, 4116-4125

[13] Zana R. \& Tondre C. (1971 :)Biopolymers ,10, 2635-2638

[14] O'Brien, W.D. Jr \& Dunn F. (1972): J.Phys Chem., 76,528-533

[15] Applegate K. Slutsky ,L. J. \& Parker R.C (1968): J.Am. Chem. Soc.90, 6909-6913

[16] White R.D., Slutsky L.J. \& Pattison S. (1971): J.Phys.Chem.75, 161-163

[17] Burke J.J.,. Hammes G.G \& Lewis T.B. (1965): J. Chem Phys. 42, 3520-3525,

[18] O'Brien W.D., Jr. \& Dunn F. (1971): J.Acoust. Soc. Am. 501213-1215,

[19] Zana R. \& Lang J. (1970): J.Phys Chem, 74, 2734-2736,

[20] Dunn F. \& Kessler L.W. (1970): J.Phys Chem, 74, 2736 